Article

\title{
Estimate and Temporal Monitoring of Height and Diameter of the Canopy of Recently Transplanted Coffee by a Remotely Piloted Aircraft System
}

\author{
Nicole Lopes Bento (D), Gabriel Araújo e Silva Ferraz*(D), Rafael Alexandre Pena Barata, Daniel Veiga Soares, \\ Lucas Santos Santana ${ }^{(D)}$ and Brenon Diennevan Souza Barbosa
}

check for

updates

Citation: Bento, N.L.; Ferraz,

G.A.e.S.; Barata, R.A.P.; Soares, D.V.;

Santana, L.S.; Barbosa, B.D.S.

Estimate and Temporal Monitoring of

Height and Diameter of the Canopy

of Recently Transplanted Coffee by a

Remotely Piloted Aircraft System.

AgriEngineering 2022, 4, 207-215.

https://doi.org/10.3390/

agriengineering 4010015

Academic Editor: Travis Esau

Received: 8 December 2021

Accepted: 22 February 2022

Published: 24 February 2022

Publisher's Note: MDPI stays neutral with regard to jurisdictional claims in published maps and institutional affiliations.

Copyright: (c) 2022 by the authors. Licensee MDPI, Basel, Switzerland. This article is an open access article distributed under the terms and conditions of the Creative Commons Attribution (CC BY) license (https:// creativecommons.org/licenses/by/ $4.0 /)$
Department of Engineering, Federal University of Lavras-UFLA, Aquenta Sol 3037, Lavras 37200-000, MG, Brazil; nicolelbento@gmail.com (N.L.B.); rafaelpenabarata@gmail.com (R.A.P.B.); daniel.veiga@rehagro.com.br (D.V.S.); lucas.unemat@hotmail.com (L.S.S.); b.diennevan@outlook.com (B.D.S.B.) * Correspondence: gabriel.ferraz@ufla.br

\begin{abstract}
Digital agriculture is fundamental to potential improvements in the field by optimizing processes and providing intelligent decision making. This study aims to calculate the height and canopy diameter of recently transplanted coffee plants over three periods of crop development using aerial images, verify statistical differences between field measurements and aerial images, estimate linear equations between field data and aerial images, and monitor the temporal profile of the growth and development of the cultivar understudy in the field based on information extracted from aerial images through a Remotely Piloted Aircraft System (RPAS). The study area comprises a recently transplanted five-month-old Coffea arabica L. cultivar IAC J10 with information of height and crown diameter collected in the field and aerial images obtained by RPAS. As a result, it was possible to calculate the height and diameter of the canopy of coffee plants by aerial images obtained by RPAS. The linear estimation equation for height and crown diameter was determined with satisfactory results by coefficients $R$ and $R^{2}$ and performance metrics MAE, RMSE, and regression residuals, and it was possible to monitor the temporal profile of the height of the coffee cultivar in the field based on aerial images.
\end{abstract}

Keywords: precision agriculture; remote sensing; UAV

\section{Introduction}

Brazil is currently the largest producer and exporter of coffee in the world, and Minas Gerais is a prominent state in the country, according to the first survey of the year 2022 by the National Supply Company-CONAB, with an estimated production of 3.342 tons of coffee, which represents $16.8 \%$ more compared to 2021 [1]. It is a noteworthy fact that in 2020, despite the pandemic scenario, the country broke records in the production and export of grain in the world [2]. In this sense, a search is underway for technological improvement in the coffee culture, which allows for gains in productivity and profitability of crops.

Digital agriculture proposes the use of technologies that aim to help the producer to monitor the rural property with the use of software and devices responsible for data collection and processing, providing early action on problems, real-time monitoring, use of optimization improvements in the field, and intelligent and efficient decision making [3]. In this way, the digital solutions act to overcome challenges that appear daily and constant obstacles in agriculture, promoting significant improvements in the development of agricultural activities [4].

RPA is a typical application of digital agriculture, acting as a tool for the characterization, mapping, monitoring, study, and management of environmental and agricultural properties, due to the possibility of obtaining periodic information with applicability to 
different areas and lower costs when compared to traditional methodologies [5]. Added to this, this tool allows the coffee grower to manage their production more simply and assertively, directing objectives and promoting important gains in the fields, aiming to maximize the profitability of crops, making agribusiness more competitive [6].

In this sense, the application of digital agriculture to the study of the recently transplanted coffee tree is essential since it is a perennial culture in which the development and initial monitoring are of fundamental importance to obtain good future results. In contrast, treatment and management of the cultures and the behavior of the plant in this initial stage will be crucial for its future development and, consequently, the crop's productivity. Thus, the use of precision and digital agriculture data by RPAS is promising and applicable in the context of studies and development of the coffee culture, as evidenced in coffee studies by Chemura et al. [7], Oliveira et al. [8], Santos et al. [5], Marin et al. [9], Santana et al. [10], and Barbosa et al. [11]. Studies on plant development are strongly correlated with lifespan, seed mass, and ability to compete for light [12]; however, despite the simplicity of measurement, these can be time-consuming to collect in the field, especially in studies with large areas. Thus, the objective was to calculate and estimate equations for height and crown diameter of recently transplanted coffee trees by RPAS data, verify statistical differences between data collected in the field and data obtained by RPAS, and monitor the height profile in three stages of plant development coffee trees.

\section{Materials and Methods}

\subsection{Area of Interest}

The crop is located in the municipality of Santo Antônio do Amparo, Minas Gerais, between the meridians 506,000 and 508,000 $\mathrm{m} \mathrm{W}$ and parallels 7680,000 and 7690,000 $\mathrm{m} \mathrm{S,}$ in the UTM zone 23S projection and Sirgas 2000 geodetic reference in the Campos das Vertentes zone (Figure 1). It has an average altitude of $1022.00 \mathrm{~m}$ and is inserted in the Atlantic Forest Biome, with soil classified as dystrophic red-yellow latosol [13] and climate classified as humid subtropical (Cwb) [14].

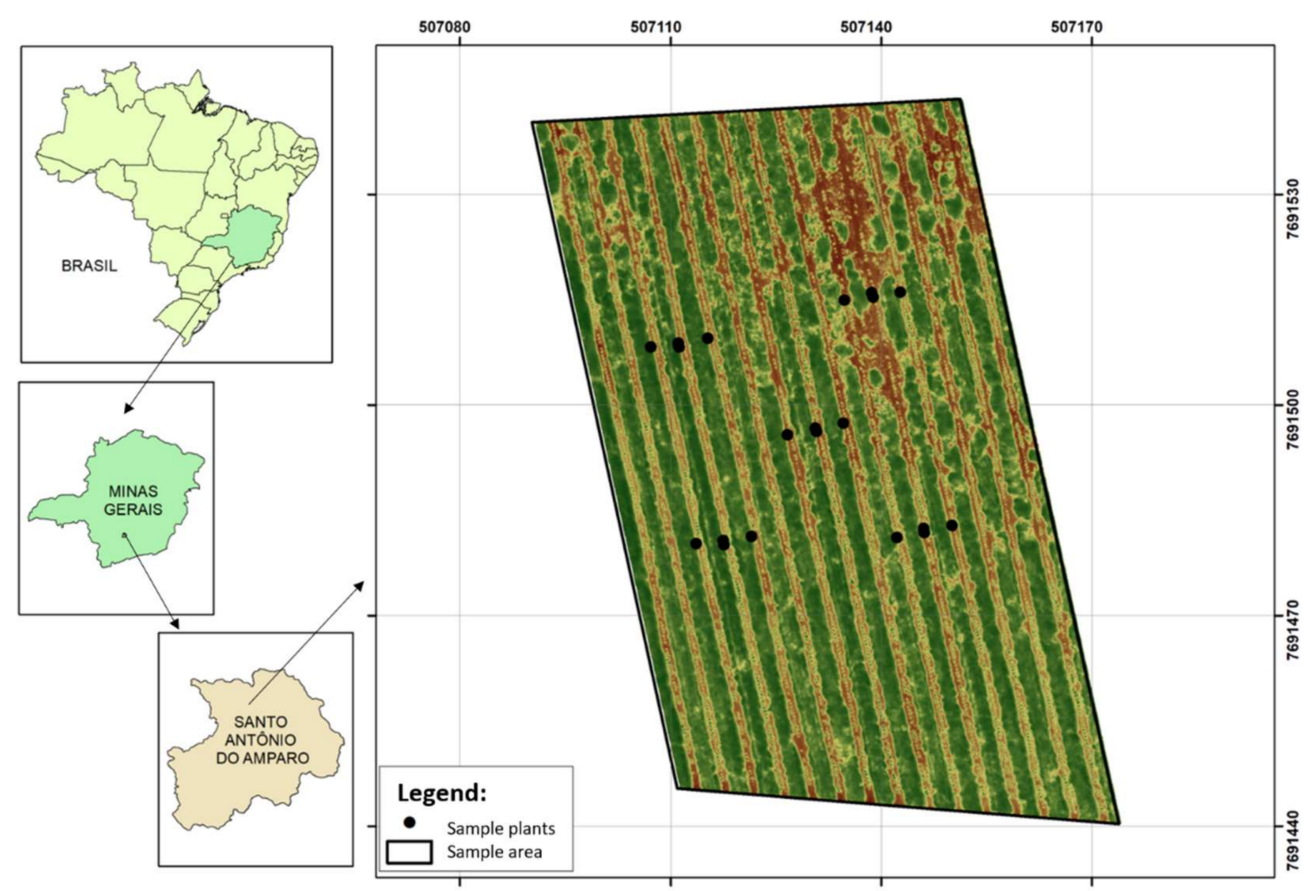

Figure 1. Location map.

The study area comprises 0.60 hectares of the recently transplanted coffee crop at the age of 5 months of Coffea arabica L. of cultivar Bourbon Yellow (IAC J10), according to the National Registry of Cultivars. The area configuration consists of 15 planting lines 
with 200 plants per row, spacing of $3.8 \mathrm{~m}$ between rows, and $0.5 \mathrm{~m}$ between plants. Five sampling points were homogeneously and systematically distributed in the study area, with each sampling point comprising four study sampling plants, two plants located in the central line and two other plants located in each of the sidelines, according to the proposed methodology in [15], totaling twenty sample plants in the study area.

\subsection{Field Measurements}

The study of height and crown diameter variables in recently transplanted coffee cultivars is essential since these variables show phases of formation, development, and growth of plants in the field, and thus emphasizes the importance of monitoring such variables in the field.

Three study periods were considered, covering the development of the cultivar in the field. The first considers the plant with 8 months post-transplantation (8 mpt-July 2019), the second with 12 months post-transplantation (12 mpt-November 2019), and the third with 16 months post-transplantation (16 mpt-March 2020). In each study date and sample plant, information on height and crown diameter was collected with measurements in the field and through images obtained by RPAS.

In field measurements, height information was collected, with the measurement of the neck to the point of insertion of the terminal bud, and the crown diameter, with the measurement of the longest branch length in the horizontal direction, both with the help of a conventional measuring ruler. Concomitant to the data collected in the field, RPAS flights were carried out to obtain area images of the study plants.

\subsection{RPAS-Based Data Collection and Processing}

In this study, the RPA Matrice 100 (DJI) with an embedded sensor referring to the Parrot Sequoia multispectral camera (MICASENSE) was used, and we considered only the use of the RGB sensor for the proposed objective. The flight plan was carried out in the Precision Flight software (PRECISION HAWK), and the flights kept the parameters set at $30 \mathrm{~m}$ for flight height aboveground land (AGL), $8 \mathrm{~m} / \mathrm{s}$ for flight speed, $80 \% \times 80 \%$ for forward frontal overlap, flight direction transverse to planting line, and standardized flight time between 12:00 and 13:00 h. The captured RGB images were $16 \mathrm{MP}$, with definition of $4608 \times 3456$ pixels, focal length of $4.88 \mathrm{~mm}$, the average size was $2.80 \mathrm{MB}$ (per image), spatial resolution of $0.8 \mathrm{~cm}$, and 'time lapse' capture parameters, with an interval fixed according to the calculation of overlap and height of $1.1 \mathrm{~s}$.

The processing of RBG images collected by RPAS is based on the principles of traditional stereoscopic photogrammetry, using the SfM algorithm, which is based on the use of several superimposed images to obtain geometry characteristics, enabling the generation of 2D and 3D point clouds through conventional cameras and thus allowing the study of measurement characteristics of different objects of study [16,17].

The processing of aerial images took place in the Pix4D Mapper software (PIX4D SA), with all items configured in high resolution. Initially, the correction of the reference system for Sirgas 2000 UTM zone 23 S was carried out, followed by the alignment of the images of each flight using triangulation, automatic measurement, and creation of link points, generating the dense cloud of points, the texture of the image, and thus enabling the generation of digital terrain modeling of both the Digital Surface Model (DSM) and the Digital Terrain Model (DTM), as well as the orthomosaic of the area for each study date.

\subsection{Statistics and Data Analysis}

The height data of the aerial images were obtained in ArcGIS 10.4 Software (ESRI) in a GIS environment, for each studied plant, through the set of functions of the AcrToolbox in the 'Algebra of Maps' tool through the subtraction between the Digital Surface Model by Digital Terrain Model according to Equation (1):

$$
\mathrm{H}=\mathrm{DSM}-\mathrm{DTM}
$$


where H is the height $(\mathrm{cm})$, DSM is the Digital Surface Model $(\mathrm{cm})$, and DTM is the Digital Terrain Model (cm).

The diameter of the canopy of plants by aerial images was obtained by measuring the longest horizontal axis based on the ruler tool for measuring distances in ArcGIS 10.4 software.

Based on data collected in the field and data obtained through aerial images, initially, the descriptive statistics of the data were verified, allowing the identification and possible elimination of outliers. Subsequently, the statistical differences between the sampling points for the three study dates were tested between the data measured in the field and the data calculated by the aerial images obtained by the RPAS, using the $t$-test at $5 \%(p<0.05)$ probability.

Then, the determination of the equation was verified through linear regression analysis $(Y=\beta 0+\beta 1 X)$ to model the relationship of the variables using the estimated (RPAS image data) and measured data (field data), based on the values of correlation coefficient (R) and coefficient of determination $\left(R^{2}\right)$. The adequacy of the proposed models was evaluated through the performance metrics of Mean Absolute Error (MAE) and Root Mean Square (RMSE), and the regression residuals were calculated. All procedures were performed using R software (R DEVELOPMENT CORE TEAM) and Orange Canvas [18].

Finally, the temporal development of cultivars in the field was verified, based on information obtained from aerial images, by surveying the monitoring profile of the cultivar for the three study dates with the choice of 10 random plants in the study area in the ArcGIS 10.4 software and the R software. For that, the ArcGIS 10.4 software was used to determine and cut out the study plants and the fieldDraw tool from the FieldImage package in the $\mathrm{R}$ software [19] was used to obtain a profile with extracted and plotted information and a graphical line format. This information allows the visualization of the development and growth of the coffee culture in the field, serving as a useful tool for monitoring and intelligent decision making.

\section{Results and Discussion}

\subsection{In-Field Canopy Height and Diameter Measurements and Aerial Images}

Initially, the study variables' exploratory analysis and descriptive statistics were performed for the data variables of height and crown diameter measured in the field and calculated by aerial images for the three post-transplantation periods and twenty study plants described in Table 1.

Table 1. Descriptive statistics, in centimeters $(\mathrm{cm})$, for height and crown diameter variables measured in the field and by aerial images for the three periods of study.

\begin{tabular}{cccccc}
\hline Periods & Variables & Mean & Minimum & Maximum & Dispersal \\
\hline \multirow{3}{*}{$8 \mathrm{mpt}$} & Field Height & 44.90 & 34.00 & 61.00 & 0.16 \\
& Image Height & 46.20 & 27.00 & 68.00 & 0.27 \\
& Field Diameter & 41.70 & 29.00 & 61.00 & 0.18 \\
& Image Diameter & 42.30 & 32.00 & 57.00 & 0.17 \\
\hline \multirow{3}{*}{$12 \mathrm{mpt}$} & Field Height & 67.75 & 56.00 & 91.00 & 0.13 \\
& Image Height & 73.50 & 53.00 & 89.00 & 0.14 \\
& Field Diameter & 67.60 & 55.00 & 101.00 & 0.15 \\
& Image Diameter & 64.10 & 46.00 & 99.00 & 0.20 \\
\hline \multirow{3}{*}{$16 \mathrm{mpt}$} & Field Height & 93.20 & 68.00 & 110.00 & 0.11 \\
& Image Height & 94.30 & 82.00 & 123.00 & 0.11 \\
& Field Diameter & 94.35 & 66.00 & 121.00 & 0.14 \\
\hline
\end{tabular}

As shown in Table 1, the values calculated from aerial images did not show a fixed tendency to overestimate or underestimate the height and crown diameter variables, with a notable fluctuation between such information. The values of the variables determined by 
field measurement in this study corroborate studies in recently transplanted coffee trees, such as those by Tatagiba et al. [20], Marana et al. [21], and Souza et al. [22].

Collecting crown height and diameter data manually in the field is difficult, especially when performed in large coffee areas, so using RPAS images to obtain such variables is interesting, as it optimizes the collection of such information in a reliable and automated way. This study proves that this methodology is satisfactory and efficient and corroborates the results found by Santos et al. [5], however with application in adult coffee trees.

The extraction of this information in the field can be unfeasible when performed manually, and the use of technologies that implement the concepts of remote sensing (RS), such as RPA, can be an alternative to meet this need. Considering the recent emergence of RPA in agricultural applications and the limited number of studies involving the estimation of plant height, especially in coffee trees at the beginning of the field development cycle, the applicability of this study is highlighted.

\subsection{Statistical Differences between Field Measurements and Aerial Images}

The proximity between the data measured in the field and the data calculated based on the aerial images was evidenced in the previous topic; however, the statistical differences for the data of height and diameter of the crown measured in the field and calculated by the aerial images, for the three seasons and twenty plants of the study, are presented in Figure 2.
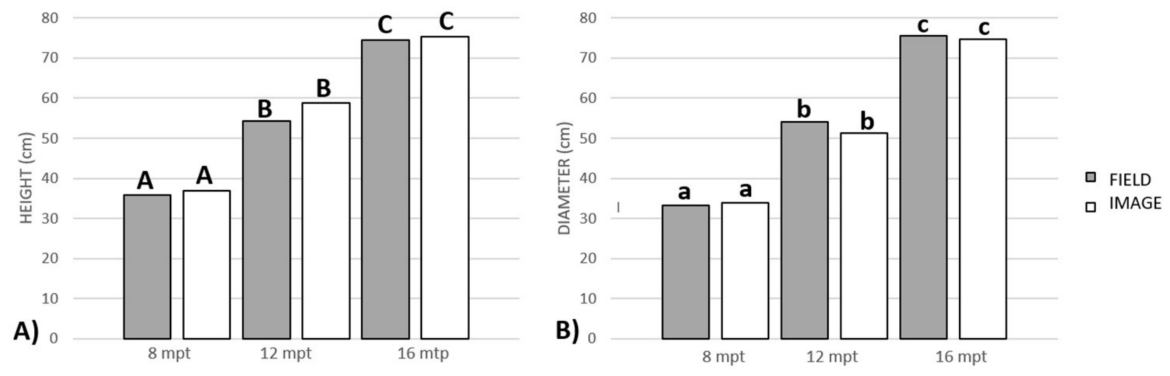

Figure 2. Statistical differences between height (A) and crown diameter $(\mathbf{B})$, in centimeters (cm), measured in the field and by aerial images for the three periods of study. Legend: Equal letters in the same variable and time of study indicate a non-significant statistical difference at $5 \%$ probability according to the $t$-test.

Figure 2 shows a bar graph of the average of the values measured in the field and through the information obtained by the aerial images. The statistical hypothesis tested was that the estimates of the height and canopy diameter of the coffee plants produced by the two methods would be the same. The $t$-test results for each variable and study period were not significant (Figure 2), indicating that there is no significant difference between the two methods of determining the measured variables for both study periods and, consequently, it shows the ability to estimate the variables by the method of digital image processing.

Normally, when collecting data manually in the field, plants are chosen randomly, and the number may not represent plot dimensions. With the application of the digital image processing method, the sample size can consider some plants or all plants in the plot, according to the need for the study and/or investigation, resulting in more significant crop sampling data related to better time optimization in the field, highlighting the effectiveness of the application of technology.

Studies by Santos et al. [5] and Panagiotidis et al. [16] revealed good results for estimating height in adult coffee and forest trees using area images from RPAS, and Bendig et al. [23] highlighted the use of RPAS for indirect measurements and for monitoring the spatial variation of plant height, as evidenced in this study. 


\subsection{Estimation of the Linear Equation for Height and Crown Diameter Variables Using Aerial Images}

The correlations for the height and crown diameter variables between the data measured in the field and the data calculated through aerial images were tested. The Pearson (R) correlation coefficient results were 0.885 for the height variable and 0.934 for the crown diameter variable, demonstrating a strong correlation between the data.

Based on the linear regression between the study variables, a coefficient of determination $\left(\mathrm{R}^{2}\right)$ of 0.873 was found for the height variable and 0.784 for the crown diameter variable; therefore, it is possible to propose an equation to estimate the height and crown diameter from aerial images obtained by RPAS, as described in Figure 3.
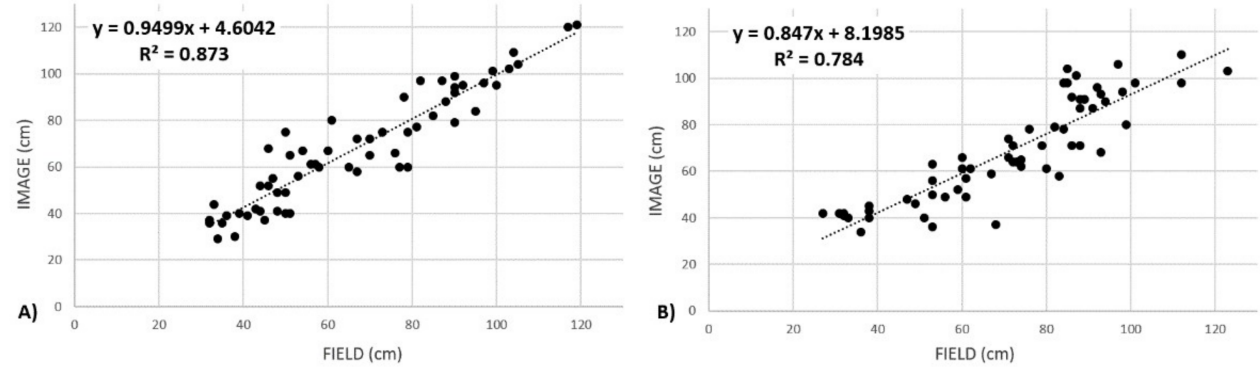

Figure 3. Linear regression, $R^{2}$, and estimation equation for the height (A) and crown diameter (B) variables, in centimeters $(\mathrm{cm})$.

For the proposed models, MAE and RMSE were respectively 7.93 and $9.07 \mathrm{~cm}$ for the height variable and respectively 6.54 and $8.54 \mathrm{~cm}$ for the crown diameter variable, indicating representativeness of the precision of the estimated model, with the described error values indicative of the good precision of the model for the variables analyzed according to such performance metrics.

For adult coffee plants, Santos et al. [5] found a good estimate of linear correlation between aerial image data and data measured in the field, also enabling the definition of a correspondence equation with good performance metrics; however, for recently transplanted coffee trees, no works were found in the literature.

To evaluate the effectiveness of the regression model, the regression residuals were calculated for the observed pairs between data measured in the field and data obtained by aerial images of RPAS for the variables of height and crown diameter. The dispersion of residuals is under the assumptions of regression, in which the residuals are presumably distributed randomly around zero.

\subsection{Monitoring the Temporal Development Profile of Coffee Plants}

The temporal monitoring profile of plant height for the three study periods is described in Figure 4.

Based on Figure 4, according to the description of the height profile of plants for the temporal monitoring of the three periods studied, the increase in height in coffee plants can be seen. It is known and expected that the height of the coffee tree increases with age, which was observed in all plants, with linear growth for the periods of study after plant transplantation in the field. Considering the study cultivar, Bourbon Yellow (IAC J10), the information described in this study is consistent with the considerations presented in the literature with a description of medium height according to the Embrapa Coffee Research Consortium [24].

The plants studied for monitoring the temporal profile presented heights varying from 42.22 to $59.91 \mathrm{~cm}$ for season $1,56.14$ to $79.51 \mathrm{~cm}$ for season 2, and from 104.55 to $137.43 \mathrm{~cm}$ for season 3 . The development of the plagiotropic lateral branches of the coffee plants shows approximation between the plants and an increase in lateral height in the distance between plants in the line. Initially, aerial images do not capture the influence of height between plants, and the collected value refers to the soil (Figure 4A). Whereas, 
for the following study periods (Figure 4B,C), the increase in height between plants was captured by aerial images, with additions consistent with the increase in plant height, emphasizing the development of the lateral branches that in the future may further fill the region between the plants in the row and make it difficult to identify and individualize the coffee plants.
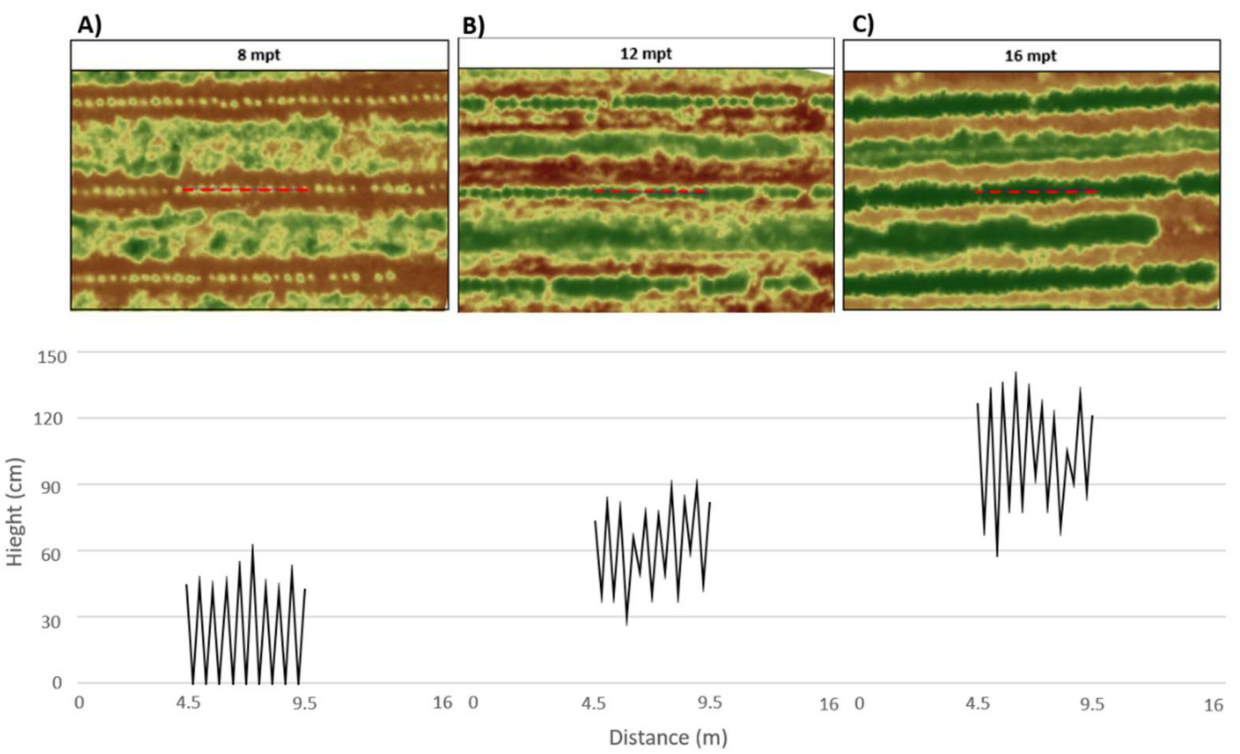

Figure 4. Temporal height profile, in centimeters $(\mathrm{cm})$, of 10 sample plants considering 3 different periods of study, according to the dashed red graphic line for: (A) $8 \mathrm{mpt}$, (B) $12 \mathrm{mpt}$, and (C) $16 \mathrm{mpt}$.

Estimating the monitoring of the height variable is important since producers can monitor the development cycle of the coffee plant in the field, evidencing its behavior and highlighting any uniformity to the parameters described in the literature according to the implemented cultivar. The determination of these variables is fundamental since they can be related to the responses of coffee plants, such as biomass reduction, water stress, the occurrence of pests and diseases, nutritional deficiencies, changes in chlorophyll content, and productivity [25-27]. Therefore, it emphasizes the importance of studies of this applicability characteristic, especially in recently transplanted coffee plants, which have characteristics of perennial plants, with initial impacts that can affect the entire longevity of the plant in the field, coupled with the fact that there are few studies aimed at coffee trees at the beginning of their development cycle in the field.

\section{Conclusions}

Height and crown diameters of recently transplanted coffee trees were calculated in three development periods through aerial images, with no statistically significant differences being detected between the values of the study variables measured in the field and those obtained indirectly by aerial images.

A linear estimation equation was determined for the height and crown diameter variables based on information obtained from aerial images, with satisfactory results, as evidenced by the correlation and determination coefficients ( $R$ of 0.88 and 0.93 , and $R^{2}$ of 0.87 and 0.78 for height and diameter, respectively), and by MAE and RMSE performance metrics (7.93 and $9.07 \mathrm{~cm}$ and 6.54 and $8.54 \mathrm{~cm}$ for the height and diameter variables, respectively).

It was possible to follow the temporal profile of the variable height of coffee plants in the initial phase of development, evidencing the applicability of studies with remote sensors coupled to RPA for the study, monitoring, and investigation of recently transplanted coffee trees. 


\begin{abstract}
Author Contributions: Conceptualization, N.L.B. and G.A.e.S.F.; methodology, N.L.B. and G.A.e.S.F.; software, N.L.B.; validation, N.L.B.; formal analysis, N.L.B., R.A.P.B., D.V.S., L.S.S., and B.D.S.B.; investigation, N.L.B., R.A.P.B., D.V.S., L.S.S., and B.D.S.B.; resources, N.L.B., R.A.P.B., D.V.S., L.S.S., and B.D.S.B.; data curation, N.L.B. and G.A.e.S.F.; writing-original draft preparation, N.L.B. and G.A.e.S.F.; writing-review and editing, N.L.B. and G.A.e.S.F.; visualization, N.L.B. and G.A.e.S.F.; supervision, G.A.e.S.F.; project administration, N.L.B. and G.A.e.S.F.; funding acquisition, G.A.e.S.F. All authors have read and agreed to the published version of the manuscript.
\end{abstract}

Funding: This research was funded by the Embrapa Café- Consórcio Pesquisa Café, project approved no 234/2019, the National Council for Scientific and Technological Development (CNPq), the Coordination for the Improvement of Higher Education Personnel (CAPES), the Federal University of Lavras (UFLA).

Institutional Review Board Statement: Not applicable.

Informed Consent Statement: Not applicable.

Data Availability Statement: Data sharing not applicable.

Acknowledgments: We would like to thank the Embrapa Brazilian Coffee Research Consortium, the National Council for Scientific and Technological Development (CNPq), the Coordination for the Improvement of Higher Education Personnel (CAPES), the Federal University of Lavras (UFLA), and the Farm Samambaia.

Conflicts of Interest: The authors declare no conflict of interest.

\title{
References
}

1. Companhia Nacional de Abastecimento-(CONAB). Acompanhamento da Safra Brasileira de Café-Primeiro Levantamento; Boletim Safra; Observatório Agrícola: Brasília, Brazil, 2022; Volume 1.

2. Companhia Nacional de Abastecimento-(CONAB). Acompanhamento da Safra Brasileira de Café-Quarto Levantamento; Boletim Safra; Observatório Agrícola: Brasília, Brazil, 2020; Volume 5.

3. Lioutas, E.D.; Charatsari, C. Smart farming and short food supply chains: Are they compatible? Land Use Policy 2020, $94,104541$. [CrossRef]

4. Klerkx, L.; Rose, D. Dealing with the game-changing technologies of Agriculture 4.0: How do we manage diversity and responsibility in food system transition pathways? Glob. Food Sec. 2020, 24, 100347. [CrossRef]

5. Dos Santos, L.M.; Barbosa, B.D.D.S.; Diotto, A.V.; Maciel, D.T.; Xavier, L.A. Biophysical parameters of coffee crop estimated by UAV RGB images. Precis. Agric. 2020, 21, 1227-1241. [CrossRef]

6. MAPA. Ministério da Agricultura, Pecuária e Abastecimento. Agricultura de Precisão/Ministério da Agricultura, Pecuária e Abastecimento. Secretaria de Desenvolvimento Agropecuário e Cooperativismo-Brasília: Mapa/ACS. 2009. Available online: http://www.abc.gov.br/training/informacoes/InstituicaoMAPA_en.aspx (accessed on 5 December 2021).

7. Chemura, A.; Mutanga, O.; Dube, T. Integrating age in the detection and mapping of incongruous patches in coffee (Coffea arabica L.) plantations using multi-temporal Landsat 8 NDVI anomalies. Int. J. Appl. Earth Obs. Geoinf. 2017, 57, 1-13. [CrossRef]

8. Oliveira, A.J.; Assis, G.A.; Guizilini, V.; Faria, E.R.; Souza, J.R. Segmenting and Detecting Nematode in Coffee Crops Using Aerial Images. In Lecture Notes in Computer Science (including subseries Lecture Notes in Artificial Intelligence and Lecture Notes in Bioinformatics); Springer: Cham, Switzerland, 2019; Volume 11754 LNCS, pp. 274-283. ISBN 9783030349943.

9. Marin, D.B.; Alves, M.D.C.; Pozza, E.A.; Gandia, R.M.; Cortez, M.L.J.; Mattioli, M.C. Sensoriamento remoto multiespectral na identificação e mapeamento das variáveis bióticas e abióticas do cafeeiro. Rev. Ceres 2019, 66, 142-153. [CrossRef]

10. Santana, L.S.; Ferraz, G.A.E.S.; Cunha, J.P.B.; Santana, M.S.; Faria, R.D.; Marin, D.B.; Rossi, G.; Conti, L.; Vieri, M.; Sarri, D. Monitoring errors of semi-mechanized coffee planting by remotely piloted aircraft. Agronomy 2021, 11, 1224. [CrossRef]

11. Barbosa, B.D.S.; Ferraz, G.A.E.S.; Dos Santos, L.M.; Santana, L.S.; Marin, D.B.; Rossi, G.; Conti, L. Application of rgb images obtained by uav in coffee farming. Remote Sens. 2021, 13, 2397. [CrossRef]

12. Moles, A.T.; Warton, D.I.; Warman, L.; Swenson, N.G.; Laffan, S.W.; Zanne, A.E.; Pitman, A.; Hemmings, F.A.; Leishman, M.R. Global patterns in plant height. J. Ecol. 2009, 97, 923-932. [CrossRef]

13. Santos, H.G.D.; Jacomine, P.K.T.; Anjos, L.H.C.D.; Oliveira, V.A.D.; Lumbreras, J.F.; Coelho, M.R.; Almeida, J.A.D.; Araújo Filho, J.C.D.; Oliveira, J.B.D.; Cunha, T.J.F. Brazilian system of soil classification-SBCS; 5a ; Embrapa: Rio de Janeiro, Brazil, 2018; ISBN 978-85-7035-800-4 1.

14. Alvares, C.A.; Stape, J.L.; Sentelhas, P.C.; de Moraes Gonçalves, J.L.; Sparovek, G. Köppen's climate classification map for Brazil. Meteorol. Zeitschrift 2013, 22, 711-728. [CrossRef]

15. Moreira da Silva, F.; Silva de Oliveira, M.; Paiva Custódio, A.A.; Ferreira Ponciano Ferraz, P. Variabilidade espacial dos atributos da planta de uma lavoura cafeeira. Rev. Cienc. Agron. 2017, 48, 81-91. [CrossRef]

16. Panagiotidis, D.; Abdollahnejad, A.; Surový, P.; Chiteculo, V. Determining tree height and crown diameter from high-resolution UAV imagery. Int. J. Remote Sens. 2017, 38, 2392-2410. [CrossRef] 
17. Martínez-Carricondo, P.; Agüera-Vega, F.; Carvajal-Ramírez, F.; Mesas-Carrascosa, F.J.; García-Ferrer, A.; Pérez-Porras, F.J. Assessment of UAV-photogrammetric mapping accuracy based on variation of ground control points. Int. J. Appl. Earth Obs. Geoinf. 2018, 72, 1-10. [CrossRef]

18. Demšar, J.; Curk, T.; Erjavec, A.; Gorup, Č.; Hočevar, T.; Milutinovič, M.; Možina, M.; Polajnar, M.; Toplak, M.; Starič, A.; et al. Orange: Data Mining Toolbox in Python. J. Mach. Learn. Res. 2013, 14, 2349-2353.

19. Matias, F.I.; Caraza-Harter, M.V.; Endelman, J.B. FIELDimageR: An R package to analyze orthomosaic images from agricultural field trials. Plant Phenome J. 2020, 3, 1-6. [CrossRef]

20. Tatagiba, S.D.; Pezzopane, J.E.M.; dos Reis, E.F. Crescimento vegetativo de mudas de café arábica (Coffea arabica L.) submetidas a diferentes níveis de sombreamento. Coffee Sci. 2010, 5, 251-261.

21. Marana, J.P.; Miglioranza, É.; Fonseca, É.D.P.; Kainuma, R.H. Índices de qualidade e crescimento de mudas de café produzidas em tubetes. Ciência Rural 2008, 38, 39-45. [CrossRef]

22. Souza, L.S.; Losasso, P.H.L.; Oshiiwa, M.; Garcia, R.R.; Goes Filho, L.A. Efeitos das faixas de controle do capim-braquiária (Brachiaria decumbens) no desenvolvimento inicial e na produtividade do cafeeiro (Coffea arabica L.). Planta Daninha 2006, 24, 715-720. [CrossRef]

23. Bendig, J.; Bolten, A.; Bennertz, S.; Broscheit, J.; Eichfuss, S.; Bareth, G. Estimating Biomass of Barley Using Crop Surface Models (CSMs) Derived from UAV-Based RGB Imaging. Remote Sens. 2014, 6, 10395-10412. [CrossRef]

24. Carvalho, C.H.S. Cultivares de Café; Embrapa: Brasília, Brazil, 2007.

25. Da Cunha, J.P.; Sirqueira, M.A.; Hurtado, S. Estimating vegetation volume of coffee crops using images from unmanned aerial vehicles. Eng. Agrícola 2019, 39, 41-47. [CrossRef]

26. Carrijo, G.L.A.; Oliveira, D.E.; de Assis, G.A.; Carneiro, M.G.; Guizilini, V.C.; Souza, J.R. Automatic detection of fruits in coffee crops from aerial images. In Proceedings of the 2017 Latin American Robotics Symposium (LARS) and 2017 Brazilian Symposium on Robotics (SBR), Curitiba, Brazil, 8-11 November 2017; IEEE: Piscataway, NJ, USA, 2017; Volume 2017, pp. 1-6.

27. Chemura, A.; Mutanga, O.; Dube, T. Remote sensing leaf water stress in coffee (Coffea arabica L.) using secondary effects of water absorption and random forests. Phys. Chem. Earth Parts A/B/C 2017, 100, 317-324. [CrossRef] 